\title{
Analysis of CDKN1C in fetal growth restriction and pregnancy
}

\section{loss [version 1; peer review: 2 approved]}

\author{
Jenifer P. Suntharalingham (iD1*, Miho Ishida1*, Federica Buonocore (iD), \\ Ignacio del Valle1, Nita Solanky ${ }^{1}$, Charalambos Demetriou${ }^{1}$, Lesley Regan², \\ Gudrun E. Moore ${ }^{1 *}$, John C. Achermann ${ }^{1 *}$
}

\begin{abstract}
${ }^{1}$ Genetics and Genomic Medicine, UCL Great Ormond Street Institute of Child Health, University College London, London, WC1N $1 \mathrm{EH}, \mathrm{UK}$

2Obstetrics and Gynaecology Department, St Mary's Hospital, Imperial College London, London, W2 1NY, UK

* Equal contributors
\end{abstract}

\begin{tabular}{l}
\hline V1 First published: 23 Jan 2019, 8:90 \\
https://doi.org/10.12688/f1000research.15016.1 \\
Latest published: $21 \mathrm{Apr}$ 2020, 8:90 \\
https://doi.org/10.12688/f1000research.15016.2 \\
\hline
\end{tabular}

\section{Abstract}

Background: Cyclin-dependent kinase inhibitor 1C (CDKN1C) is a key negative regulator of cell growth encoded by a paternally imprinted/maternally expressed gene in humans. Loss-of-function variants in CDKN1C are associated with an overgrowth condition (Beckwith-Wiedemann Syndrome) whereas "gain-of-function" variants in CDKN1C that increase protein stability cause growth restriction as part of IMAGe syndrome (Intrauterine growth restriction, Metaphyseal dysplasia, Adrenal hypoplasia and Genital anomalies). As two families have been reported with CDKN1C mutations who have fetal growth restriction (FGR)/Silver-Russell syndrome (SRS) without adrenal insufficiency, we investigated whether pathogenic variants in CDKN1C could be associated with isolated growth restriction or recurrent loss of pregnancy.

Methods: Analysis of published literature was undertaken to review the localisation of variants in CDKN1C associated with IMAGe syndrome or fetal growth restriction. CDKN1C expression in different tissues was analysed in available RNA-Seq data (Human Protein Atlas). Targeted sequencing was used to investigate the critical region of CDKN1C for potential pathogenic variants in SRS ( $n=58), F G R(n=26)$, DNA from spontaneous loss of pregnancy $(n=21)$ and women with recurrent miscarriages $(n=71)$ (total $n=176)$.

Results: All published single nucleotide variants associated with IMAGe syndrome are located in a highly-conserved "hot-spot" within the PCNA-binding domain of CDKN1C between codons 272-279. Variants associated with familial growth restriction but normal adrenal function currently affect codons 279 and 281. CDKN1C is highly expressed in the placenta compared to adult tissues, which may contribute to the FGR phenotype and supports a role in pregnancy maintenance. In the patient cohorts studied no pathogenic

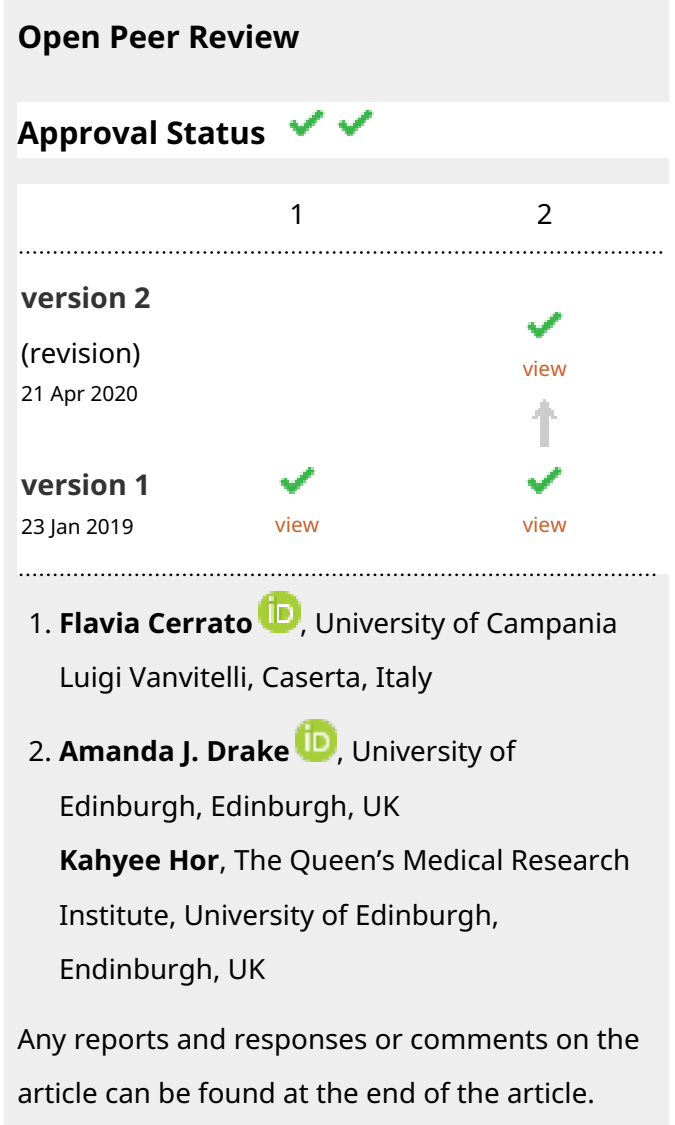


variants were identified in the PCNA-binding domain of CDKN1C.

Conclusion: CDKN1C is a key negative regulator of growth. Variants in a very localised "hot-spot" cause growth restriction, with or without adrenal insufficiency. However, pathogenic variants in this region are not a common cause of isolated fetal growth restriction phenotypes or loss-of-pregnancy/recurrent miscarriages.

\section{Keywords}

CDKN1C, intra-uterine growth restriction, fetal growth restriction, Silver-Russell syndrome, IMAGe syndrome, adrenal, placenta, recurrent miscarriage

\section{$\pm \mathbf{J a h}$}

This article is included in the UCL Child Health

gateway.

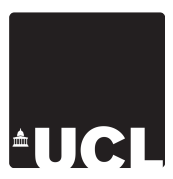

This article is included in the University College

London collection.

\section{Corresponding author: John C. Achermann (j.achermann@ucl.ac.uk)}

Author roles: Suntharalingham JP: Data Curation, Formal Analysis, Investigation, Methodology, Validation, Visualization, Writing Review \& Editing; Ishida M: Data Curation, Formal Analysis, Investigation, Methodology, Writing - Review \& Editing; Buonocore F: Formal Analysis, Methodology, Writing - Review \& Editing; del Valle I: Data Curation, Formal Analysis, Visualization, Writing - Review \& Editing; Solanky N: Investigation, Project Administration, Resources; Demetriou C: Conceptualization, Investigation, Writing - Review \& Editing; Regan L: Funding Acquisition, Project Administration, Resources; Moore GE: Conceptualization, Funding Acquisition, Project Administration, Resources, Supervision, Writing - Review \& Editing; Achermann JC: Conceptualization, Formal Analysis, Funding Acquisition, Methodology, Project Administration, Supervision, Validation, Visualization, Writing - Original Draft Preparation

Competing interests: G.E.M and L.R are co-directors of Baby Bio Bank. N.S. is the Baby Bio Bank manager.

Grant information: J.C.A. is a Wellcome Trust Senior Research Fellow in Clinical Science (grant 209328/Z/17/Z) with research support from Great Ormond Street Hospital Children's Charity (grant V2518) and the NIHR GOSH BRC (IS-BRC-1215-20012). The views expressed are those of the author(s) and not necessarily those of the NHS, the NIHR, or the Department of Health. The Baby Bio Bank was funded by Wellbeing of Women. M.I. and C.D. are funded by the UK MRC.

The funders had no role in study design, data collection and analysis, decision to publish, or preparation of the manuscript.

Copyright: (c) 2019 Suntharalingham JP et al. This is an open access article distributed under the terms of the Creative Commons Attribution License, which permits unrestricted use, distribution, and reproduction in any medium, provided the original work is properly cited.

How to cite this article: Suntharalingham JP, Ishida M, Buonocore $\mathrm{F}$ et al. Analysis of CDKN1C in fetal growth restriction and pregnancy loss [version 1; peer review: 2 approved] F1000Research 2019, 8:90 https://doi.org/10.12688/f1000research.15016.1

First published: 23 Jan 2019, 8:90 https://doi.org/10.12688/f1000research.15016.1 


\section{Introduction}

Cyclin-dependent kinase inhibitor 1C (CDKN1C, also known as P57/kip2) (OMIM 600856) is a key negative regulator of cell proliferation that is encoded by a paternally imprinted (maternally expressed) gene on the short arm of chromosome 11 (11p15.4) in humans (Stampone et al., 2018).

Consistent with its role in growth and development, maternallyinherited loss-of-function variants in CDKN1C are found in approximately $5-10 \%$ of individuals with the "overgrowth" condition, Beckwith-Wiedemann Syndrome (BWS) (OMIM 130650) (Eggermann et al., 2014). Clinical features of BWS include macrosomia, hyperinsulinism and adrenal tumors.

In contrast, gain-of-function variants in CDKN1C have been shown to cause growth restriction as part of IMAGe syndrome (OMIM 614732) (Arboleda et al., 2012). IMAGe syndrome is characterised by fetal/Intrauterine growth restriction, Metaphyseal dysplasia, Adrenal hypoplasia and Genital anomalies (in males, usually relatively mild hypospadias and undescended testes) as well as additional features such as hearing loss and hypercalciuria (Bennett et al., 1993; Vilain et al., 1999).

To date, children with IMAGe syndrome have all been found to harbour pathogenic single nucleotide variants (SNVs) in a very specific region of the PCNA-binding domain of CDKN1C (Arboleda et al., 2012; Cabrera-Salcedo et al., 2017). These changes potentially lead to increased activity through increasing protein stability, thereby preventing cell cycle progression into S phase (Borges et al., 2015; Hamajima et al., 2013).

More recently, SNVs in the PCNA-binding domain of CDKN1C have been reported in families with maternally-inherited fetal growth restriction (FGR) without adrenal insufficiency and in familial Silver-Russell syndrome (SRS) (OMIM 180860) (Brioude et al., 2013; Kerns et al., 2014). SRS is characterised by variable clinical features including fetal and post-natal growth restriction, relative macrocephaly, feeding difficulties and characteristic facies. SRS is also described as phenotypically and genotypically opposite to BWS and approximately half of the molecular anomalies are attributed to Chr11p15.5 imprinting clusters, including several individuals with maternal duplication of the locus containing CDKN1C (Bonaldi et al., 2011; Boonen et al., 2016; Schönherr et al., 2007).
These findings suggest that the growth restriction phenotype associated with CDKN1C may be more variable and adrenal insufficiency is not always present.

The aim of this study was therefore to review published CDKN1C variants associated with FGR/IUGR phenotypes, to study $C D K N 1 C$ expression in different tissues, and to analyse the critical region in CDKN1C in a range of growth restriction and adverse pregnancy phenotypes, with a hypothesis that severe restriction of feto-placental growth may, in some situations, result in pregnancy loss or recurrent miscarriage.

\section{Methods}

Review of pathogenic SNVs and population variability

A PubMed search was undertaken (March 2018) using the search terms "CDKN1C", "human" and "growth", or "IMAGe syndrome". Reports focusing on growth restriction phenotypes associated with single nucleotide variants were considered. Population variation in $C D K N 1 C$ was assessed using the gnomAD browser (http://gnomad.broadinstitute.org; accessed April 2018) (Lek et al., 2016). Protein conservancy analysis was performed using ClustalW in Jalview (Waterhouse et al., 2009).

\section{Analysis of CDKN1C expression}

RNA-Seq data for CDKN1C expression was obtained with specific permission from the Human Protein Atlas (Human Protein Atlas available from www.proteinatlas.org) and re-drawn in $\mathrm{R}$ (version 3.4.2) (Uhlen et al., 2015).

\section{Study cohorts}

The following growth restriction cohorts were included in this study: 1) SRS ( $n=58)$ (isolated, non-familial) diagnosed on consensus criteria and where maternal uniparental disomy or H19/IGF2:IG-DMR (also known as ICR1 or IC) hypomethylation had been excluded (Wakeling et al., 2017); 2) FGR (n=26) (isolated, non-familial) defined as birth weight less than the 3rd centile, as part of the Baby Bio Bank cohort (UCL-GOS Institute of Child Health \& St Mary's Imperial College London) (Leon et al., 2016). Additional analysis was undertaken in DNA from 3) products of conception (POC) $(n=21)$ where there had been a spontaneous loss of pregnancy and 4) mothers who had a history of recurrent miscarriages $(n=71)$ (at least three miscarriages) where an underlying cause was not known (Baby Bio Bank). An overview of these cohorts is provided in Table 1.

Table 1. Overview of the cohorts studied.

\begin{tabular}{|c|c|c|c|}
\hline Cohort & Number & Characteristics & Sequencing \\
\hline $\begin{array}{l}\text { Silver-Russell } \\
\text { Syndrome }\end{array}$ & 58 & $\begin{array}{l}\text { Silver-Russell syndrome; maternal uniparental disomy of chromosome } 7 \text { or } \\
\text { H19/IGF2:IG-DMR hypomethylation excluded }\end{array}$ & Sanger \\
\hline IUGR/FGR & 26 & $\begin{array}{c}\text { DNA from children with intra-uterine growth restriction (birth weight }<3^{\text {rd }} \\
\text { percentile) (Baby Bio Bank) }\end{array}$ & $\begin{array}{l}\text { Next-generation sequencing } \\
\quad \text { (mean read depth } 37.8 \text { ) }\end{array}$ \\
\hline $\begin{array}{l}\text { Products of } \\
\text { conception }\end{array}$ & 21 & DNA from lost products of conception between 9-11 weeks gestation & $\begin{array}{l}\text { Next-generation sequencing } \\
\quad(\text { mean read depth 60.1) }\end{array}$ \\
\hline $\begin{array}{l}\text { Recurrent } \\
\text { miscarriages }\end{array}$ & 71 & $\begin{array}{c}\text { DNA from mothers with recurrent miscarriages }(>3) \text { and usually a history of } \\
\text { live births }\end{array}$ & $\begin{array}{l}\text { Next-generation sequencing } \\
\text { (mean read depth } 31.5 \text { ) }\end{array}$ \\
\hline
\end{tabular}

Abbreviations: FGR, fetal growth restriction; IUGR, intrauterine growth restriction 


\section{Consent}

Ethical Committee approval for the Baby Bio bank was obtained from the Trent Derby Ethics Committee (09/H0405/30) and Ethical Committee approval for the Silver Russell trios was from GOSH Research Ethics Committee (REC No. 1278). Written informed consent was obtained from participants or parents. DNA was extracted from blood lymphocytes, placental tissue or products of conception, as appropriate.

\section{Genomic analysis of CDKN1C by Sanger Sequencing}

Direct Sanger Sequencing was undertaken for SRS patients to analyse the PCNA-binding region (codons 213-316) and hotspot (codons 272-281) using primers reported previously (CCDS7738, ENST00000414822.8) (Arboleda et al., 2012). Additional primers pairs were used to sequence the 3 ' end of exon 1 and splice site (CDKN1CF: CAGGAGCCTCTCGCTGAC; CDKN1CR2: GCTGGAGGGCACAACAAC). Polymerase chain reaction (PCR) was carried out with BIOTAQ DNA Polymerase (BIOLINE, London, UK). PCR products were purified by microclean (Microzone, Haywards Heath, UK) and amplified with BigDyeTerminator v1.1, followed by sequencing on a DNA Analyzer 3070 (Applied Biosystems, California, US). The resulting read-outs were reviewed in Sequencher (v5.3: Gene Codes).

Genomic analysis of CDKN1C by targeted capture array and next generation sequencing

Targeted array capture followed by next-generation sequencing was performed for FGR samples, products of conception and mothers with a history of recurrent miscarriage.

A targeted enrichment custom HaloPlex $501 \mathrm{~kb}-2.5 \mathrm{Mb}$ HS panel (Agilent Technologies Inc.) was designed using Agilent
SureDesign to capture known and candidate genes for fetal growth disruption, including CDKN1C. This study used designs targeting either 147 (design size 1.391 Mbp) or 257 (design size $2.045 \mathrm{Mbp})$ genes.

Sequencing libraries were prepared using 50ng of genomic DNA following the manufacturer's protocol (HaloPlex HS Target Enrichment System for Illumina Sequencing version C1 from December 2016) and as described in principle previously (Guran et al., 2016). This was followed by 2 x 100bp or $2 \times 149 \mathrm{bp}$ paired end sequencing to a median read depth of $300 x$ on a NextSeq sequencer (Illumina Inc.). The bcl files were converted to fastq files using manufacturers recommended guidelines and were then analysed in SureCall software (version 4.0.1.46 (Agilent Technologies) using the HaloPlex Default Method or custom settings (minimum number of read pairs per barcode =1). Samples with a minimum read depth less than 4 at any single nucleotide position were excluded.

\section{Results}

Single nucleotide variants in CDKN1C

Review of available data revealed six publications describing isolated individuals (7) or families (4) with IMAGe syndrome and adrenal insufficiency, who had pathogenic variants in a key region of the PCNA-binding domain of CDKN1C affecting codons 272, 274, 276, 278 and 279 (Figure 1, Table 2) (Arboleda et al., 2012; Bodian et al., 2014; Brioude et al., 2013; Hamajima et al., 2013; Kato et al., 2014; Kerns et al., 2014). These codons are highly conserved amongst species (Figure 2). Multiple individuals from different ancestral backgrounds were found to have p.Asp274Asn or p.Lys278Glu changes.

Variants in CDKN1C associated with familial Silver-Russell syndrome or growth restriction but normal adrenal function were
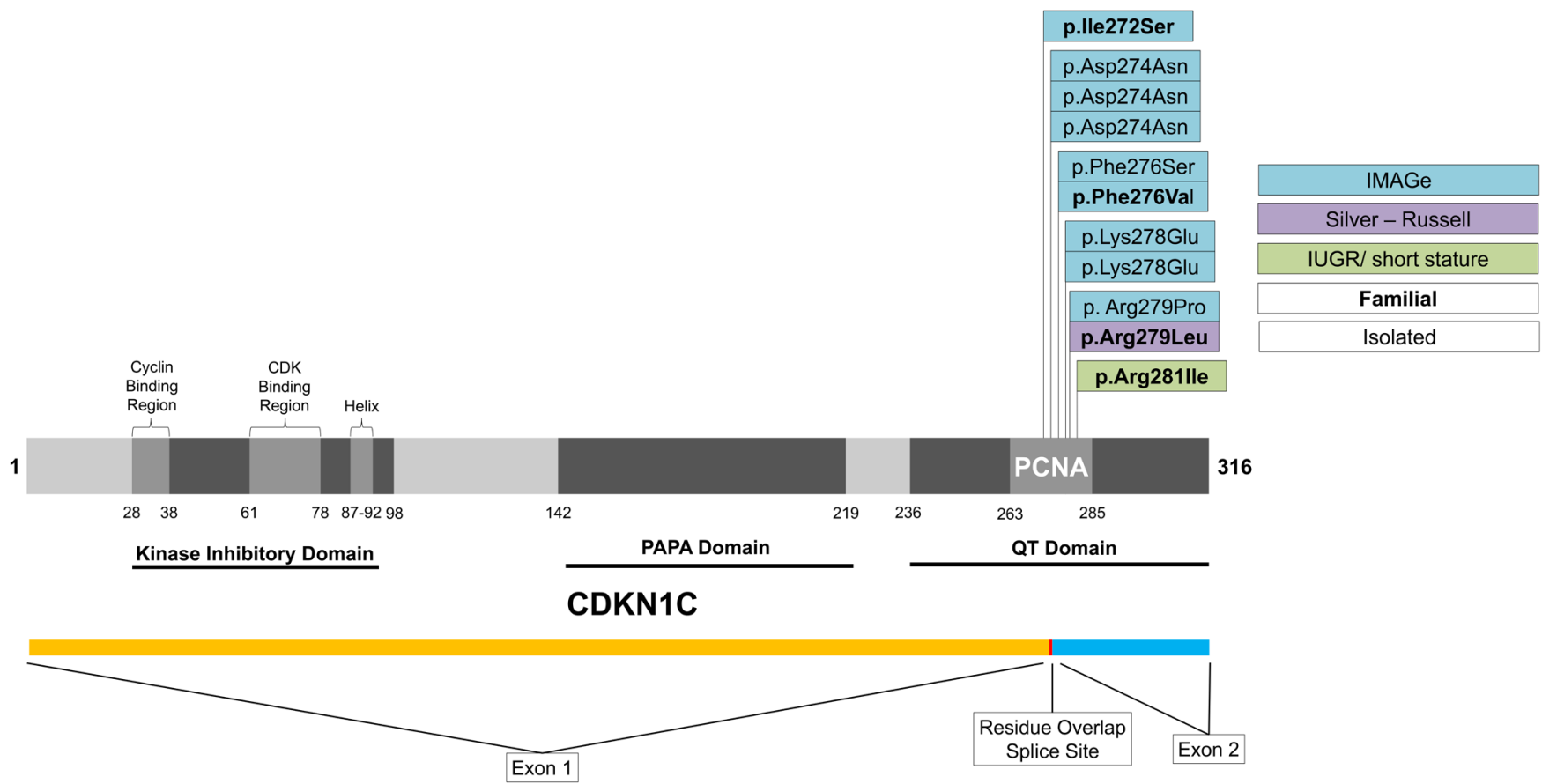

Figure 1. Schematic diagram showing the structure of CDKN1C and the clustering of pathogenic variants associated with IMAGe syndrome and/or growth restriction. 
Table 2. Reported variants in CDKN1C and associated phenotypes.

\begin{tabular}{|c|c|c|c|c|}
\hline $\begin{array}{l}\text { Nucleotide } \\
\text { variant }\end{array}$ & Protein change & Isolated/Familial & Phenotype & Reference \\
\hline c. $815 \mathrm{~T}>\mathrm{G}$ & p.lle272Ser & Familial (3) & IMAGe & Hamajima et al., 2013 \\
\hline c. $820 \mathrm{G}>\mathrm{A}$ & p.Asp274Asn & Isolated & IMAGe & Arboleda et al., 2012 \\
\hline c. $820 \mathrm{G}>\mathrm{A}$ & p.Asp274Asn & Isolated & IMAGe & Kato et al., 2014 \\
\hline c. $820 \mathrm{G}>\mathrm{A}$ & p.Asp274Asn & Isolated & IMAGe (Glucocorticoid) & Kato et al., 2014 \\
\hline c. $826 \mathrm{~T}>\mathrm{G}$ & p.Phe276Val & Familial (7) & IMAGe & Arboleda et al., 2012 \\
\hline c. $827 \mathrm{~T}>\mathrm{C}$ & p.Phe276Ser & Isolated & IMAGe & Arboleda et al., 2012 \\
\hline c. $832 A>G$ & p.Lys278Glu & Isolated & IMAGe & Arboleda et al., 2012 \\
\hline c. $832 A>G$ & p.Lys278Glu & Isolated & IMAGe (Mineralocorticoid) & Bodian et al., 2014 \\
\hline c. $836 \mathrm{G}>\mathrm{C}$ & p.Arg279Pro & Isolated & IMAGe & Arboleda et al., 2012 \\
\hline c. $836 \mathrm{G}>\mathrm{T}$ & p.Arg279Leu & Familial (9) & Silver-Russell & Brioude et al., 2013 \\
\hline c. $842 \mathrm{G}>\mathrm{T}$ & p.Arg281lle & Familial (15) & $\begin{array}{c}\text { IUGR, short stature, } \\
\text { IGT/DM }\end{array}$ & Kerns et al., 2014 \\
\hline
\end{tabular}

Abbreviations: DM, diabetes mellitus; IGT, impaired glucose tolerance; IMAGe, intrauterine growth restriction, metaphyseal dysplasia, adrenal hypoplasia congenita, genital anomalies; IUGR, intrauterine growth restriction

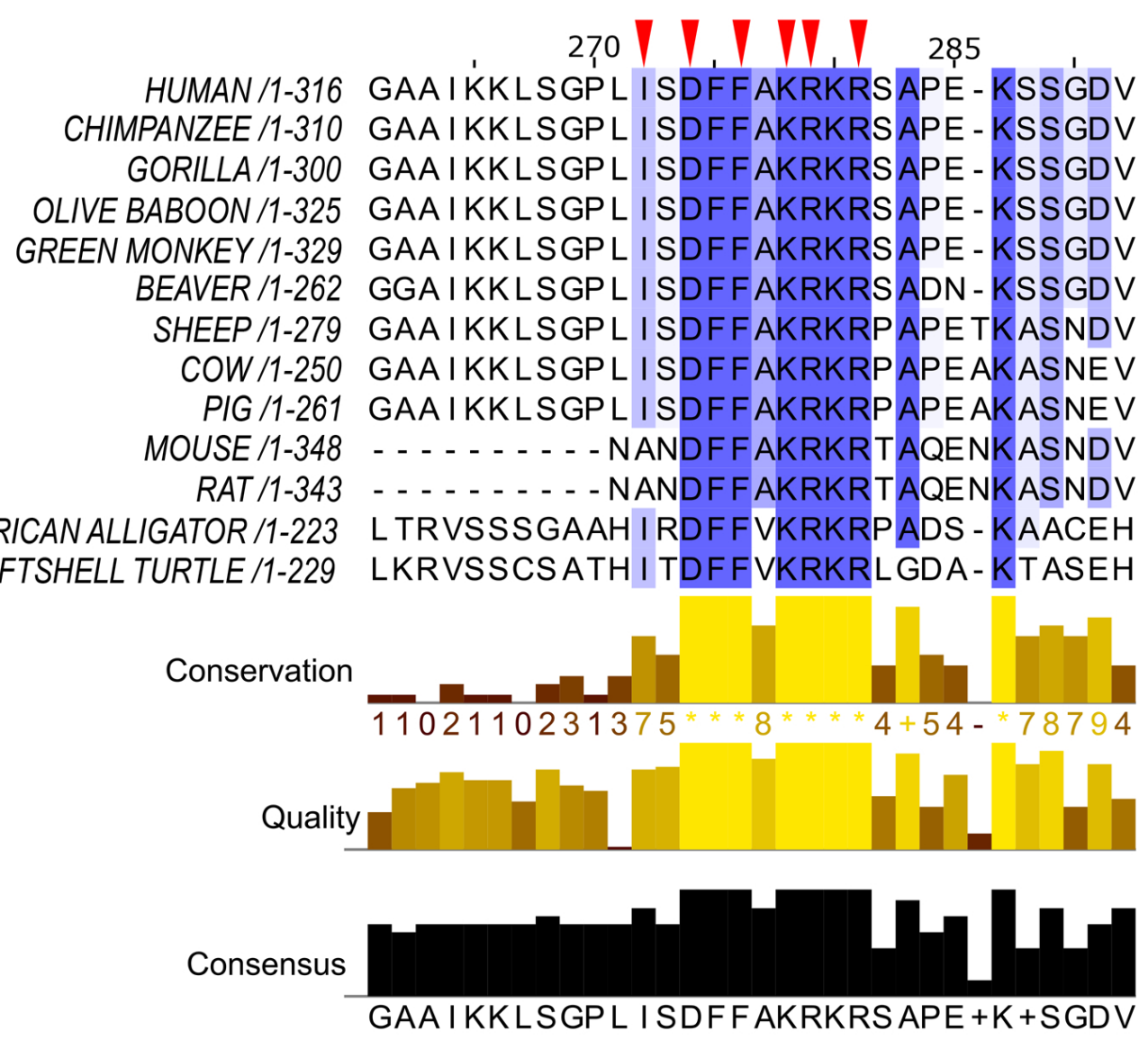

Figure 2. Amino-acid conservancy in the "hot-spot" region of CDKN1C. Red arrowheads represent codons that are mutated in IMAGe syndrome, FGR/IUGR or Silver-Russell syndrome. Yellow asterisks represent complete conservation amongst the species shown. 
found towards the carboxyl-terminal region of this "hot-spot" domain (p.Arg279Leu, p.Arg281Ile) (Figure 1).

Analysis of population data from the gnomAD browser showed a complete absence of variants in the key codons listed. Very rare heterozygous SNVs were found that are predicted to cause p.Ala277Val $(11: 2905355 \mathrm{G}>\mathrm{A} ; 1$ in 107288 alleles) and p.Ala283Val (11:2905337G $>$ A; rs776541692; 1 in 30726 alleles) changes. Of note, these codons are two of the lesser-conserved amino acids within this "hot-spot" region (Figure 2).

\section{Expression of CDKN1C in human tissue}

RNA-Seq analysis of CDKN1C in a panel of human tissues showed highest expression in the placenta (Figure 3; Human Protein Atlas data, https://www.proteinatlas.org/ ENSG00000129757-CDKN1C/tissue), with strong expression also in adipose tissue, ovary, adrenal, endometrium and kidney. Immunohistochemistry in the Human Protein Atlas repository shows strong staining in the nuclei of both decidual and trophoblastic cells (https://www.proteinatlas.org/ENSG00000129757-CDKN1C/ tissue/placenta).

\section{Analysis of CDKN1C variants in growth restriction}

Analysis of the PCNA-binding domain of CDKN1C by Sanger sequencing in a cohort of 58 children with isolated (nonfamilial) Silver-Russell syndrome did not reveal any pathogenic variants. Sequencing data for exon 2 is shown in Supplementary Data 1 (Achermann, 2018).
A next-generation sequencing approach of CDKN1C in children with IUGR/FGR $(n=26)$, products of conception $(n=21)$, and mothers with a history of recurrent miscarriage $(n=71)$ also did not reveal pathogenic variants in this region (Table 1). Details of coverage for each sample/cohort and each nucleotide is shown in Supplementary Data 2-7 (Achermann, 2018).

\section{Discussion}

CDKN1C is now well-established as a key regulator of cell cycle and growth through G1 phase cell cycle arrest. Although loss-of-function of CDKN1C is known to cause macrosomia as part of Beckwith-Wiedemann Syndrome, it is only in the past six years that "gain-of-function" variants in CDKN1C have been shown to cause growth restriction and IMAGe syndrome. These findings demonstrate clearly how opposite effects in protein function can have opposite phenotypes (Arboleda et al., 2012; Eggermann et al., 2014). Sometimes these features affect not just growth but also endocrine systems (e.g. adrenal tumours (BWS)/adrenal hypoplasia (IMAGe); congenital hyperinsulinism (BWS)/diabetes mellitus (one family with growth restriction)).

Review of published literature confirms that CDKN1C SNVs associated with IMAGe syndrome or growth restriction are all located within a "hot-spot" of the PCNA-binding domain of the protein. The exact function of this region is not clear, and the crystal structure of this region of CDKN1C has not yet been solved. Studies to date suggest pathogenic variants may increase protein stability or reduce the rate of degradation, thereby enhancing the negative effects of CDKN1C on cell cycle

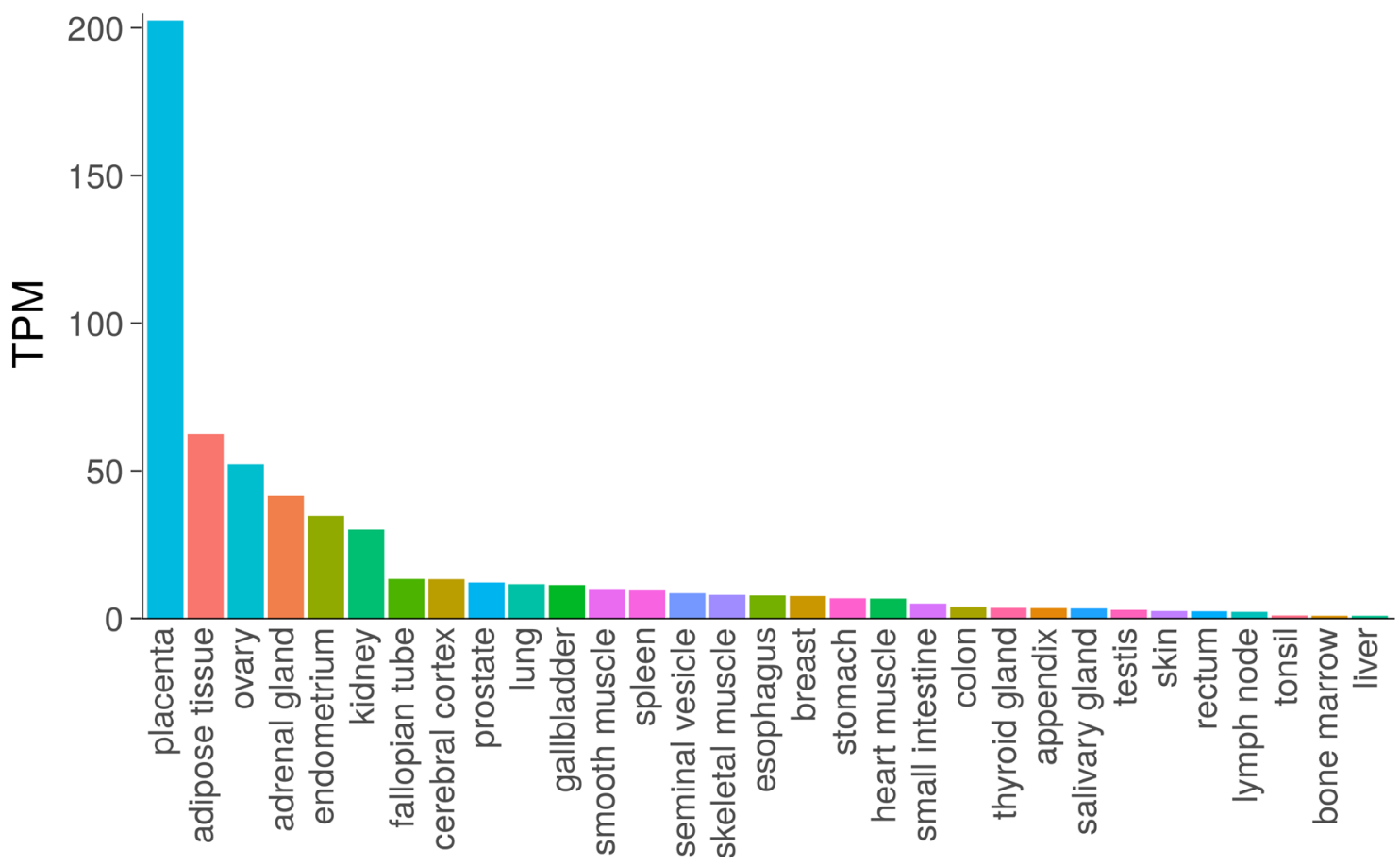

Figure 3. RNA expression of CDKN1C in placenta and different adult human tissues. Data reproduced and modified with permission from the Human Protein Atlas (www.proteinatlas.org) (Uhlen et al., 2015). TPM = Transcripts Per Million. 
progression (Borges et al., 2015; Hamajima et al., 2013). The very localised nature of these variants clearly demonstrates a key role for this region in $\mathrm{CDKN} 1 \mathrm{C}$ function.

CDKN1C is strongly expressed in fetal adrenal development as shown by qPCR and immunohistochemistry (Arboleda et al., 2012), by microarray (Del Valle et al., 2017), and RNA-Seq (unpublished). Furthermore, analysis of RNA-Seq data from the Human Protein Atlas shows marked expression in the placenta (Figure 3). Immunohistochemistry shows strong nuclear staining in both decidual and trophoblastic cells. Therefore, gain-of-function of CDKN1C in the developing placenta could have a significant contribution to the growth restriction phenotype.

Further evidence for a potential role for CDKN1C in fetal growth restriction phenotypes has emerged with reports of CDKN1C variants in familial growth restriction and familial SRS (Brioude et al., 2013; Kerns et al., 2014). Several features of IMAGe syndrome and SRS overlap, such as bi-frontal bossing and relative micrognathia. To date these children have not shown evidence of adrenal insufficiency. Whilst a lack of adrenal features could be due to underlying mosaicism or a somatic "rescue" event, as recently reported for variants in SAMD9 in the related condition MIRAGE syndrome (Buonocore et al., 2017; Narumi et al., 2016), the fact that several individuals in a family with the same CDKNIC SNV were affected provides strong evidence that the primary genomic event is influencing the phenotype rather than a rescue mechanism. Of note, review of the two SNVs associated with FGR and normal adrenal function reveals that they affect amino acids at the C-terminal region of the hotspot. In one family a charged arginine at codon 279 is replaced by a non-polar leucine, whereas a proline at this position is found in classic IMAGe syndrome. In another family, the arginine at position 281 is replaced by a non-polar isoleucine. In some situations, variants in amino-acids flanking critical motifs can be associated with milder phenotypes (Kyriakakis et al., 2017).

Despite these findings, we did not identify any CDKN1C variants in children with isolated (non-familial) SRS or IUGR/ FGR. These results are similar to data from Brioude et al. who only reported a CDKN1C variant in familial SRS and did not find variants in 68 children with an isolated condition (Brioude et al., 2013). Whilst this does not exclude CDKN1C as a potential cause of isolated or sporadic SRS/FGR, it does suggest that it is not a common cause.

Identification of such strong expression of CDKN1C in the placenta lead us to consider whether gain-of-function/increased stability of CDKN1C could be associated with loss of pregnancy or recurrent miscarriage. This hypothesis was supported further by recent studies linking placental genes to pregnancy loss (Perez-Garcia et al., 2018); a potential role for placental CDKN1C expression in fetal growth and regulation by oestrogen (Chen et al., 2018; Gou et al., 2017; López-Abad et al., 2016; Unek et al., 2014); and the fact that paternal imprinting of the gene means that a pool of deleterious variants could be present in the population and cause pregnancy loss (together with live births) in women who carry this variant and inherit it from their father.

Analysis was therefore undertaken in a cohort of mothers who had recurrent miscarriages (often together with live birth(s)) and also from products of conception. However, no variants were found in the PCNA binding domain of CDKN1C in these cohorts.

This work has several limitations. Although 176 total individuals were studied, each sub group is still relatively small and rare CDKN1C variants might be discovered if the sample size is increased. The causes of recurrent miscarriage and fetal growth restriction are clearly diverse and can be influenced by many factors, and regulatory regions or enhancers (Perez-Garcia et al., 2018; Rai \& Regan, 2006; Stalman et al., 2018; Wakeling et al., 2017). Nevertheless, this study does highlight the role of the key region of $C D K N 1 C$ in human fetal growth restriction phenotypes, and starts to address the potential role of single gene growth restriction phenotypes in more common obstetric and fetal conditions.

\section{Data availability}

Data has been uploaded to OSF: http://doi.org/10.17605/OSF. IO/Y7KZV (Achermann, 2018). Representative sequencing data for chromatograms is shown in Supplementary Data 1. Data of coverage for next generation sequencing is shown in Supplementary Data 2-7.

Data are available under the terms of the Creative Commons Zero "No rights reserved" data waiver (CC0 1.0 Public domain dedication).

Access for samples from the Baby Bio Bank is available and can be requested from the steering committee by emailing the Baby Bio Bank Manager (nita.solanky@ucl.ac.uk). More information about data access can be found on the website under the 'Protocol for the management of the Baby Bio Bank', section 15: http://www.ucl.ac.uk/tapb/sample-and-data-collectionsat-ucl/biobanks-ucl/baby-biobank/baby-biobank-documents/ BBB_SOP_version7. An application form for the use of Baby Bio Bank resources must be completed prior to application (see appendix 2 in the protocol).

\section{Grant information}

J.C.A. is a Wellcome Trust Senior Research Fellow in Clinical Science (grant 209328/Z/17/Z) with research support from Great Ormond Street Hospital Children's Charity (grant V2518) and the NIHR GOSH BRC (IS-BRC-1215-20012). The views expressed are those of the author(s) and not necessarily those of the NHS, the NIHR, or the Department of Health. The Baby Bio Bank was funded by Wellbeing of Women. M.I. and C.D. are funded by the UK MRC.

The funders had no role in study design, data collection and analysis, decision to publish, or preparation of the manuscript. 
Achermann J: Analysis of CDKN1C in Fetal Growth Restriction and Pregnancy Loss. Open Science Framework. 2018.

http://www.doi.org/10.17605/OSF.IO/Y7KZV

Arboleda VA, Lee H, Parnaik R, et al:: Mutations in the PCNA-binding domain of CDKN1C cause IMAGe syndrome. Nat Genet. 2012; 44(7): 788-792.

PubMed Abstract | Publisher Full Text | Free Full Text

Bennett J, Schrier Vergano SA, Deardorff MA: IMAGe Syndrome. GeneReviews ${ }^{\circledR}$. 1993; (Accessed: 25 April 2018).

PubMed Abstract

Bodian DL, Solomon BD, Khromykh A, et al.: Diagnosis of an imprinted-gene syndrome by a novel bioinformatics analysis of whole-genome sequences from a family trio. Mol Genet Genomic Med. 2014; 2(6): 530-538.

PubMed Abstract | Publisher Full Text | Free Full Text

Bonaldi A, Mazzeu JF, Costa SS, et al.: Microduplication of the ICR2 domain at chromosome 11p15 and familial Silver-Russell syndrome. Am J Med Genet A. Wiley-Blackwell, 2011; 155A(10): 2479-2483.

PubMed Abstract | Publisher Full Text

Boonen SE, Freschi A, Christensen R, et al:: Two maternal duplications involving the CDKN1C gene are associated with contrasting growth phenotypes. Clin Epigenetics. 2016; 8(1): 69.

PubMed Abstract | Publisher Full Text | Free Full Text

Borges KS, Arboleda VA, Vilain E: Mutations in the PCNA-binding site of CDKN1C inhibit cell proliferation by impairing the entry into $S$ phase. Cell Div. 2015; 10(1): 2

PubMed Abstract | Publisher Full Text | Free Full Text

Brioude F, Oliver-Petit I, Blaise A, et al:: CDKN1C mutation affecting the PCNAbinding domain as a cause of familial Russell Silver syndrome. J Med Genet. 2013; 50(12): 823-830.

PubMed Abstract | Publisher Full Tex

Buonocore F, Kühnen P, Suntharalingham JP, et al.: Somatic mutations and progressive monosomy modify SAMD9-related phenotypes in humans. J Clin Invest. 2017; 127(5): 1700-1713.

PubMed Abstract | Publisher Full Text | Free Full Text

Cabrera-Salcedo C, Kumar P, Hwa V, et al.: IMAGe and Related Undergrowth Syndromes: The Complex Spectrum of Gain-of-Function CDKN1C Mutations. Pediatr Endocrinol Rev. 2017; 14(3): 289-297.

PubMed Abstract

Chen XJ, Chen F, Lv PP, et al:: Maternal high estradiol exposure alters CDKN1C and IGF2 expression in human placenta. Placenta. 2018; 61: 72-79.

PubMed Abstract | Publisher Full Text

Del Valle I, Buonocore F, Duncan AJ, et al:: A genomic atlas of human adrena and gonad development [version 2; referees: 4 approved]. Wellcome Open Res. 2017; 2: 25.

PubMed Abstract | Publisher Full Text | Free Full Text

Eggermann T, Binder G, Brioude F, et al:: CDKN1C mutations: two sides of the same coin. Trends Mol Med. 2014; 20(11): 614-622.

PubMed Abstract | Publisher Full Text

Gou C Liu X, Shi X, et al: Placental Expressions of CDKN1C and KCNQ1OT1 in Monozygotic Twins with Selective Intrauterine Growth Restriction. Twin Res Hum Genet. 2017; 20(5): 389-394.

PubMed Abstract | Publisher Full Tex

Guran T, Buonocore F, Saka N, et al:: Rare Causes of Primary Adrenal Insufficiency: Genetic and Clinical Characterization of a Large Nationwide Cohort. J Clin Endocrinol Metab. 2016; 101(1): 284-292.

PubMed Abstract | Publisher Full Text | Free Full Text

Hamajima N, Johmura Y, Suzuki S, et al:: Increased protein stability of CDKN1C causes a gain-of-function phenotype in patients with IMAGe syndrome. PLOS One. Edited by He B, 2013; 8(9): e75137.

PubMed Abstract | Publisher Full Text | Free Full Text

Kato F, Hamajima T, Hasegawa T, et al.: IMAGe syndrome: clinical and genetic implications based on investigations in three Japanese patients. Clin
Endocrinol (Oxf). 2014; 80(5): 706-713.

PubMed Abstract | Publisher Full Text

Kerns SL, Guevara-Aguirre J, Andrew S, et al:: A novel variant in CDKN1C is associated with intrauterine growth restriction, short stature, and early-

adulthood-onset diabetes. J Clin Endocrinol Metab. 2014; 99(10): E2117-E2122. PubMed Abstract | Publisher Full Text | Free Full Text

Kyriakakis N, Shonibare T, Kyaw-Tun J, et al:: Late-onset X-linked adrenal hypoplasia (DAX-1, NROB1): two new adult-onset cases from a single center. Pituitary. 2017; 20(5): 585-593.

PubMed Abstract | Publisher Full Text | Free Full Text

Lek M, Karczewski KJ, Minikel EV, et al:: Analysis of protein-coding genetic variation in 60,706 humans. Nature. Nature Publishing Group, 2016; 536(7616): 285-291.

PubMed Abstract | Publisher Full Text | Free Full Text

Leon LJ, Solanky N, Stalman SE, et al.: A new biological and clinical resource for research into pregnancy complications: The Baby Bio Bank. Placenta. 2016; 46: 31-37.

PubMed Abstract | Publisher Full Text | Free Full Text

López-Abad M, Iglesias-Platas I, Monk D: Epigenetic Characterization of CDKN1C in Placenta Samples from Non-syndromic Intrauterine Growth Restriction. Front Genet. 2016; 7: 62.

PubMed Abstract | Publisher Full Text | Free Full Text

Narumi S, Amano N, Ishii T, et al:: SAMD9 mutations cause a novel multisystem disorder, MIRAGE syndrome, and are associated with loss of chromosome 7. Nat Genet. 2016; 48(7): 792-797.

PubMed Abstract | Publisher Full Tex

Perez-Garcia V, Fineberg E, Wilson R, et al.: Placentation defects are highly prevalent in embryonic lethal mouse mutants. Nature. 2018; 555(7697): 463-468. PubMed Abstract | Publisher Full Text | Free Full Text

Rai R, Regan L: Recurrent miscarriage. Lancet. 2006; 368(9535): 601-11. PubMed Abstract | Publisher Full Tex

Schönherr N, Meyer E, Roos A, et al.: The centromeric 11p15 imprinting centre is also involved in Silver-Russell syndrome. J Med Genet. BMJ Publishing Group Ltd, 2007; 44(1): 59-63.

PubMed Abstract | Publisher Full Text | Free Full Text

Stalman SE, Solanky N, Ishida M, et al.: Genetic Analyses in Small-forGestational-Age Newborns. J Clin Endocrinol Metab. 2018; 103(3): 917-925. PubMed Abstract | Publisher Full Text

Stampone E, Caldarelli I, Zullo A, et al: Genetic and Epigenetic Control of CDKN1C Expression: Importance in Cell Commitment and Differentiation, Tissue Homeostasis and Human Diseases. Int J Mol Sci. 2018; 19(4): pii: E1055. PubMed Abstract | Publisher Full Text

Uhlen M, Fagerberg L, Hallström BM, et al:: Proteomics. Tissue-based map of the human proteome. Science. 2015; 347(6220): 1260419.

PubMed Abstract | Publisher Full Text

Unek G, Ozmen A, Ozekinci M, et al.: Immunolocalization of cell cycle proteins (p57, p27, cyclin D3, PCNA and Ki67) in intrauterine growth retardation (IUGR) and normal human term placentas. Acta Histochemica. 2014; 116(3): 493-502. PubMed Abstract | Publisher Full Text

Vilain E, Le Merrer M, Lecointre C, et al:: IMAGe, a new clinical association of intrauterine growth retardation, metaphyseal dysplasia, adrenal hypoplasia congenita, and genital anomalies. J Clin Endocrinol Metab. 1999; 84(12): 4335-4340.

PubMed Abstract | Publisher Full Tex

Wakeling EL, Brioude F, Lokulo-Sodipe O, et al:: Diagnosis and management of Silver-Russell syndrome: first international consensus statement. Nat Rev Endocrinol. 2017; 13(2): 105-124.

PubMed Abstract | Publisher Full Text

Waterhouse AM, Procter JB, Martin DM, et al.: Jalview Version 2--a multiple sequence alignment editor and analysis workbench. Bioinformatics. Oxford University Press, 2009; 25(9): 1189-1191.

PubMed Abstract | Publisher Full Text | Free Full Text 


\section{Open Peer Review}

\section{Current Peer Review Status:}

\section{Version 1}

Reviewer Report 27 August 2019

https://doi.org/10.5256/f1000research.16349.r51957

(C) 2019 Drake A et al. This is an open access peer review report distributed under the terms of the Creative Commons Attribution License, which permits unrestricted use, distribution, and reproduction in any medium, provided the original work is properly cited.

\section{Amanda J. Drake}

University/British Heart Foundation Centre for Cardiovascular Science, The Queen's Medical Research Institute, University of Edinburgh, Edinburgh, UK

\section{Kahyee Hor}

University/British Heart Foundation Centre for Cardiovascular Science, The Queen's Medical Research Institute, University of Edinburgh, Endinburgh, UK

In this report Suntharalingham and colleagues investigate the extent to which variations in a known negative regulator of cell growth (CDKN1C) may be involved in isolated growth restriction or recurrent pregnancy loss.

They approach this in several ways:

1. Through analysis of published literature

2. Through analysis of CDKN1C expression in multiple tissues using available RNA-seq data

3. Targeted sequencing in a number of patient populations.

As a result of the literature search, they conclude that reported variants are located in the PCNAbinding domain of CDKN1C and therefore focus on this for their sequencing analysis. The analysis of available RNA-seq data suggests that the gene is highly expressed in placenta, suggesting it may have a role in pregnancy maintenance. Sequencing analysis revealed no pathogenic variants in the targeted region of CDKN1C suggesting this is an uncommon cause of fetal growth restriction or recurrent pregnancy loss.

The paper is well written and easy to read, with appropriate citation of the literature.

Minor comments:

1. PubMed search terms appear quite limited. Are the authors certain they have not missed any papers by not including terms such as IUGR, FGR, SGA?

2. Do the pregnancies/children in the FGR/IUGR group have any other complications? 
3. The term 'usually a history of live births' in table 2 is rather vague. Were any of these live births also affected by FGR/IUGR etc. or by pregnancy complications commonly associated with poor fetal growth e.g. pre-eclampsia.

4. In table 2 - do the numbers in brackets refer to the number of families with that variant or the number of affected individuals within a family?

Given the limited number of publications describing pathogenic mutations in the PCNA-binding domain of CDKN1C in IMAGe syndrome, familial SRS and in a single family with FGR and early adult onset diabetes, are the researchers planning to analyse other regions of the gene/its regulatory regions for other variations which may affect expression? Could they take this on to include analysis of placental gene expression/protein expression/function in assocision with analysis of sequence variation?

Is the work clearly and accurately presented and does it cite the current literature? Yes

Is the study design appropriate and is the work technically sound? Yes

Are sufficient details of methods and analysis provided to allow replication by others? Yes

If applicable, is the statistical analysis and its interpretation appropriate? Yes

Are all the source data underlying the results available to ensure full reproducibility? Yes

Are the conclusions drawn adequately supported by the results? Yes

Competing Interests: No competing interests were disclosed.

Reviewer Expertise: Epigenetics, paediatrics, fetal growth, obstetrics

We confirm that we have read this submission and believe that we have an appropriate level of expertise to confirm that it is of an acceptable scientific standard.

Author Response 08 Apr 2020

John Achermann, University College London, London, UK

Minor comments:

1. PubMed search terms appear quite limited. Are the authors certain they have not missed any papers by not including terms such as IUGR, FGR, SGA? 
Response: Thank you for this comment. We have used those additional search terms and not found any additional publications. We have modified the methods accordingly. A more recent search of CDKN1C and IMAGe has revealed an interesting additional family of two half-siblings with Silver Russell Syndrome (SRS) (Sabir et al 2019), who have a c.836 G> T variant resulting in the p.Arg279Leu change previously reported by Brioude et al. We have modified Figure 1 and Table 2 to include these important new data, which supports the hypothesis that the p.Arg279Leu change (at the edge of the PCNA-binding domain) is associated with SRS, rather than the more severe IMAGe phenotype. We have added this new reference to the paper and clarified the footnote in Table 2 to show that the numbers in parentheses refer to numbers of affected individuals within each kindred.

\section{Do the pregnancies/children in the FGR/IUGR group have any other complications?}

Response: To our knowledge this group do not have additional multisystem features.

3. The term 'usually a history of live births' in table 2 is rather vague. Were any of these live births also affected by FGR/IUGR etc. or by pregnancy complications commonly associated with poor fetal growth e.g. pre-eclampsia.

Response: This is a good point. Unfortunately, we do not have easy access to those data at present.

4. In table 2 - do the numbers in brackets refer to the number of families with that variant or the number of affected individuals within a family?

Response: Thank you for pointing this out. he number refers to the number of affected individuals within a family. We have added a footnote to clarify this.

Given the limited number of publications describing pathogenic mutations in the PCNA-binding domain of CDKN1C in IMAGe syndrome, familial SRS and in a single family with FGR and early adult onset diabetes, are the researchers planning to analyse other regions of the gene/its regulatory regions for other variations which may affect expression? Could they take this on to include analysis of placental gene expression/protein expression/function in association with analysis of sequence variation?

Response: We have analysed the rest of CDKN1C beyond the PCNA-binding domain wherever possible and did not find any variants that are clearly pathogenic (see response to reviewer 1). We did not build promoter or regulatory regions of CDKN1C into our capture design but it is an interesting point and maybe this can be addressed as more whole genome sequencing data become available. As pointed out, correlating genomic variations with placental gene and protein expression in the same individual would be a very powerful approach, if appropriate samples were available.

Competing Interests: No competing interests were disclosed. 
Reviewer Report 18 July 2019

https://doi.org/10.5256/f1000research.16349.r50625

(c) 2019 Cerrato F. This is an open access peer review report distributed under the terms of the Creative Commons Attribution License, which permits unrestricted use, distribution, and reproduction in any medium, provided the original work is properly cited.

\section{Flavia Cerrato}

Department of Environmental, Biological and Pharmaceutical Sciences and Technologies, University of Campania Luigi Vanvitelli, Caserta, Italy

In this paper Suntharalingham and coworkers investigate the involvement of CDKN1C, a negative regulator of cell proliferation and growth, in fetal growth restriction (FGR)/intrauterine growth restriction (IUGR) human conditions, pregnancy loss or recurrent miscarriage. While many loss-offunction variants have been reported associated with the overgrowth condition BeckwithWiedemann syndrome and affecting all the domains of the protein, only few variants predicted to be "gain of function", have been found associated with syndromic growth restriction conditions (IMAGe and SRS). The authors review the latter cases and find that all reported variants, associated with growth restriction, are localized in the same region inside the PCNA-binding domain, and affect evolutionary conserved amino acids.

By studying RNA-seq data available on the Human Protein Atlas website, the authors consider the high expression level of CDKN1C in placenta to hypothesize its involvement in pregnancy loss and miscarriage as a consequence of placenta restriction. Following a DNA targeted sequencing analysis restricted to the "hot spot" PCNA-binding domain in isolated cases of SRS ( $n=58)$, IUGR/FGR $(n=26)$, loss of pregnancy $(n=21)$ and women with recurrent miscarriage $(n=71)$, they do not find any pathogenic variant, concluding that pathogenic variants of this analysed region are not a common cause of these pathological conditions.

The paper is interesting and easy to read. The potential role of CDKN1C in pregnancy maintenance and its putative involvement in pregnancy loss is interesting, and an aspect that in future could be better investigated by extending the number of the cases to analyze.

It would be interesting if the authors could report the analysis of the variants extended to the CDKN1C domains other than the region corresponding to the "hot spot" PCNA-binding domain (at least for cases analysed by NGS).

Minor comments:

The authors should clarify why they have analyzed CDKN1C variants only in the isolated SRS cases, excluding the familial cases.

Most of information reported in Table 2 are already present in Figure 1, therefore Table 2 could be removed or reported as Supplementary Table.

\section{Is the work clearly and accurately presented and does it cite the current literature?}


Yes

Is the study design appropriate and is the work technically sound?

Yes

Are sufficient details of methods and analysis provided to allow replication by others? Yes

If applicable, is the statistical analysis and its interpretation appropriate?

Yes

Are all the source data underlying the results available to ensure full reproducibility? Yes

Are the conclusions drawn adequately supported by the results?

Yes

Competing Interests: No competing interests were disclosed.

Reviewer Expertise: Genomic imprinting, Imprinting disorders

I confirm that I have read this submission and believe that I have an appropriate level of expertise to confirm that it is of an acceptable scientific standard.

Author Response 08 Apr 2020

John Achermann, University College London, London, UK

The paper is interesting and easy to read. The potential role of CDKN1C in pregnancy maintenance and its putative involvement in pregnancy loss is interesting, and an aspect that in future could be better investigated by extending the number of the cases to analyze.

Response: In the revised submission, we have used the Agilent HaloPlex panel, as well as a Nonacus 3T cell target enrichment approach to add data from an additional 27 subjects (POC $(n=1)$; women with history of recurrent miscarriage $(n=7)$; Silver Russell Syndrome $(n=8)$ and fetal growth restriction $(n=11))$. We have modified Table 1, Supplementary data and Figures, and relevant places in the text, accordingly, and included a Supplementary Data 8 for Nonacus coverage. A reference for the Nonacus methods in included (Buonocore et al., 2019).

It would be interesting if the authors could report the analysis of the variants extended to the CDKN1C domains other than the region corresponding to the "hot spot" PCNA-binding domain (at least for cases analysed by NGS).

Response: Although our focus was on the PCNA-binding domain, we agree it is valid to look at regions outside of the hotspot and thank the reviewer (and reviewer 2) for the suggestion. 
Analysis of CDKN1C using the gnomAD browser (accessed March 2020) shows an expected number of synonymous changes $(\mathrm{o} / \mathrm{e}=1.06(0.86-1.31))$ but fewer missense $(0 / \mathrm{e}=0.51(0.42$ $0.63)$ ) and pLoF changes (o/e $=0(0-0.53)$ ) than expected. ( https://gnomad.broadinstitute.org/gene/ENSG00000129757?dataset=gnomad_r2_1)

Based on the fact that random variants within a gene are more likely to cause disruption rather than gain-of-function, the low number of observed missense changes is more likely to represent an intolerance to disruption and loss of function associated with overgrowth and Beckwith-Wiedemann Syndrome, rather than rare gain of function changes associated with FGR/IMAGe syndrome.

We have undertaken an extended analysis of data for the gene. We did not detect any category 1 variants (nonsense, frameshift, canonical splice site variants) at all, which is not surprising, as these would be loss of function and predicted to be associated with overgrowth.

We only identified two category 2 (non-synonymous missense) variants in the cohort, both in women who have had recurrent miscarriages. One of these is a 9:9.2906703A>G variant (rs201715947) predicted to result in a p.Leu6Pro change that is present in gnomAD with allelic frequency of 0.0001102 (8/72604). The other variant is a 9:g.2906589C $>$ T predicted to result in a p. Arg44His. This variant is not present in gnomAD but a p.Arg44Leu is present in one male. Although the SIFT score for this variant suggests it is deleterious, we find that prediction models are not always reliable for gain-of-function effects. On balance, we do not feel that either of these variants are likely to be clinically pathogenic although we cannot say this definitively. We have commented on this in the revised results. More certain is our finding that there is not a large pool of additional CDKN1C variants in our cohort outside of the PCNA binding domain.

\section{Minor comments:}

- The authors should clarify why they have analyzed CDKN1C variants only in the isolated SRS cases, excluding the familial cases.

Response: Our cohort was only made up of sporadic Silver Russell Syndrome subjects; we had no familial cases. We have mentioned this in the methods.

- Most of information reported in Table 2 are already present in Figure 1, therefore Table 2 could be removed or reported as Supplementary Table 2.

Response: We agree there is some overlap, but we would prefer to keep both in the main body of text as Figure 1 shows the structure of CDKN1C and position of variants, and Table 2 shows nucleotide data, whether mineralocorticoid or glucocorticoid was given, and links to the original references.

Competing Interests: No competing interests were disclosed. 
The benefits of publishing with F1000Research:

- Your article is published within days, with no editorial bias

- You can publish traditional articles, null/negative results, case reports, data notes and more

- The peer review process is transparent and collaborative

- Your article is indexed in PubMed after passing peer review

- Dedicated customer support at every stage

For pre-submission enquiries, contact research@f1000.com 